\title{
Entrevista com PAULO FRANCHETTI
}

\author{
Por Solange Fiuza Cardoso YOKOZAWA (UFG/Goiânia) \\ e Antônio Donizeti PIRES (UNESP/Araraquara)
}

\begin{abstract}
1) Você publicou, em 2002, a novela $O$ sangue dos dias transparentes; em 2007, os haicais que escreveu ao longo de vários anos e selecionou e reuniu em Oeste; em 2009, o conjunto de poesia fescenina Escarnho e, em 2010, o livro de poesia lírica Memória futura. Esses livros representam projetos literários bastante diversos. Como explicar a necessidade dessa diversidade de dicção e de expressão?
\end{abstract}

$\mathrm{Na}$ verdade, não sei explicar. Como quase todo mundo que escreve, comecei cedo. E só escrevia poesia. Sempre li (e ainda leio) mais poesia do que prosa. E comecei publicando poesia, pois, sem contar algumas aventuras que seria melhor deixar esquecidas, o primeiro livro que publiquei "a sério" foi uma coletânea de haicais, que saiu em 1994, numa parceria de Massao Ohno e Aliança Cultural Brasil-Japão. O Oeste constitui, na verdade, uma retomada desse primeiro livro, acrescentado agora dos poemas escritos ao longo dos 15 anos seguintes. Memória futura, embora não seja haicai, creio que tem com ele, a partir do título, algum ar de família: a poesia como registro ou gesto de resgate.

Assim também sucede com os poemas de Escarnho, apesar do gênero ser tão diverso. Foram nascendo ao longo do tempo, nos intervalos. A vida acadêmica é muitas vezes difícil de suportar. Nos momentos de mais raiva ou indignação, escrevia esses poemas, quase sempre parodiando algum texto clássico, e os enviava ao Alcir Pécora. Ríamos muito com eles e eles nos ajudavam a suportar o embate. Surgiram, assim, como parte duma estratégia de sobrevivência num meio que deveria ser o meu, mas com o qual tenho ainda hoje muita dificuldade. Mas sempre os vi como pertencendo ao domínio do privado. Por isso pedi ao editor que fizesse apenas 98 exemplares, que ficaram fora do comércio e que foram dados de presente a quem pudesse ter interesse nesse particular exercício literário. 
Já o livro de prosa reúne um conjunto de textos escritos num curto intervalo de tempo, por volta dos meus quarenta anos. A situação ficcional está dada nas partes que abrem e encerram essa novela fragmentária - que também pode ser lida como um livro de contos. Cada um desses textos foi escrito de uma só vez, seguindo um só impulso e de forma muito dolorida. Por isso o retrabalho foi longo. E igualmente penoso.

De modo que posso apenas dizer: nunca tive algo que pudesse descrever como projeto literário. $\mathrm{O}$ que fui escrevendo atendeu sempre a alguma necessidade obscura, que, no meu caso, é o único motor da escrita.

2) Para além da verve satírica e do senso de observação do novelista, o olhar do poeta lírico parece se sobrepor às suas outras orientações criativas. Sente-se poeta antes de tudo?

Talvez, no sentido que minha inclinação preferencial de escrita é fixar os contornos de uma paisagem interior ou registrar, em poucas palavras, uma percepção súbita.

3) Você publicou muito jovem dois livros de poesia: Várias vozes, aos 20 anos, e Indigo blues, aos 30. Do segundo, aproveitou, em Memória futura, o poema "Na parede do quarto". Mas ainda não encontramos nessas publicações primeiras o poeta que se dá a conhecer no livro de 2010. Que função esses exercícios de poesia da juventude tiveram, se acha que tiverem, na depuração da sua palavra poética?

Esses livrinhos nem são a rigor juvenis, o que lhes aumenta a responsabilidade e o embaraço. A seu favor têm o caráter doméstico, desprovido de ambições maiores: o primeiro foi uma publicação do centro acadêmico da faculdade; o segundo foi um folheto mimeografado, para distribuição aos amigos.

Quando me lembro deles, apenas torço para que eu não tenha, daqui a alguns anos, com relação aos livros deste momento, o mesmo desconforto. Entretanto, sinto que há, no segundo, uns cinco ou seis poemas que não envergonham. Deles, aproveitei um só, para que ficasse incrustado no livro novo, como um memento. 
4) Em Memória futura, há apropriações diretas e explicitadas, como de Yeats e Hopkins, respectivamente, nos poemas "Leda" e "Beleza maculada". Mas, no campo das influências formativas, a presença drummondiana (o Drummond de Claro enigma), já incorporada, transubstanciada, parece ser ainda mais significativa. Qual a importância de Drummond para o poeta Paulo Franchetti? E para a poesia brasileira contemporânea?

É provável que a presença mais significativa nos meus poemas seja mesmo a de Drummond, principalmente o Drummond de Novos poemas e Claro enigma. Não há nada na poesia brasileira que me agrade tanto. Quanto à segunda parte da pergunta, não creio que haja dúvida sobre a importância de Drummond para muita poesia brasileira contemporânea. Como a de João Cabral, sua obra não é contornável pelos que surgiram depois. E como há vários Drummonds, sua marca é múltipla, o que a torna talvez menos discernível, à primeira vista, do que, por exemplo, a de João Cabral ou de Paulo Leminski.

5) Diferentemente daqueles que entendem o haicai como sacada lírica ou irônica, a sua prática da forma clássica japonesa remonta diretamente ao modelo proposto por Bashô. Poderia falar sobre a sua relação, como crítico e como poeta, com o haicai?

Quando estudei a Poesia Concreta, no mestrado, a questão do ideograma - da escrita chinesa - me interessou muito. Além do que pude aprender lendo textos sobre o ideograma, julguei que valeria a pena conhecer um pouco uma língua na qual ele fosse utilizado. Cheguei a assistir a algumas aulas de chinês, num templo taoísta, mas logo vi que seria impraticável. Então me matriculei numa escola de japonês, em Campinas, onde aprendi o silabário, uns tantos kanjis e rudimentos de caligrafia. Meu interesse não era, porém, falar japonês. Era compreender o funcionamento da escrita e, principalmente, estar apto a ler haicais. E também queria entender um pouco aquela cultura que os tinha originado. Quis a sorte que, após estudar o básico na escola, onde dividia a classe com crianças que já falavam a língua, me visse na contingência de começar a carreira acadêmica no Mato Grosso. Sem escola de japonês e sem bibliotecas que permitissem a continuidade de um trabalho de pesquisa em literatura brasileira, aproveitei o ano que passei naquele Estado para me dedicar integralmente ao estudo do 
taoísmo e do budismo, e a ler tudo o que tinha levado, em inglês e francês, sobre haicai. De volta a Campinas, pedi à minha colega Elza Doi, na Unicamp, que me ensinasse japonês por meio da leitura de haicai. Desse trabalho, em que líamos e traduzíamos haicais todas as manhãs de quarta-feira, nasceu o livro Haikai - antologia e história. Só depois de publicar esse livro comecei a escrever haicais com alguma regularidade. E sempre me pareceu que o que o haicai tinha a nos ensinar, aquilo em que consistia o seu interesse para nós, não era a forma do terceto, nem os aspectos que ele poderia ter em comum com poemas da nossa própria cultura. O haicai me interessa como alteridade, como exercício de uma maneira de ver o mundo, de estar na linguagem, que cerceia o que é mais "natural" para alguém que escreve poesia ocidental. Uma poesia objetiva, que tem na modéstia um dos valores estéticos centrais. Uma poesia que não busca a síntese, mas somente produzir, com o mínimo de elementos, o necessário para que se delineie uma cena ou sensação, na qual o leitor possa encontrar um eco de suas emoções ou experiências. Daí que minha crítica de haicai se oriente pelos valores tradicionais e que eu sempre tenha buscado - nas oficinas de haicai que tenho coordenado, nos textos que publiquei em livros e revistas ou na internet - dirigir o olhar para o haicai tal como definido e praticado a partir de Bashô.

\section{6) E com a poesia fescenina?}

Sempre gostei mais, na lírica trovadoresca, da poesia satírica. Entre a cantiga de amigo e as de escárnio e maldizer, sempre preferi ler as últimas. E sempre gostei de ler a poesia pornográfica e satírica produzida ao longo dos séculos. Nesse caminho, tenho certo orgulho de ter sido um dos primeiros a dar atenção ao conjunto da poesia cômica, satírica, pornográfica ou de non sense da nossa segunda geração romântica. Além disso, eu gosto de verso medido, e leio muita poesia tradicional. De modo que os esquemas rítmicos me são familiares e fáceis de reproduzir. Mas o verso medido, o poema de forma fixa, rimado, não me parece ter lugar na contemporaneidade. A não ser como paródia ou como sátira. Isso tudo, junto com a vontade de rir de pessoas que se levavam muito a sério e expunham a cada passo o ridículo da sua pose, me levou à prática da poesia fescenina, parte da qual foi reunida em Escarnho. 
7) Depois do Modernismo, a poesia concreta, que você muito frequentou como pesquisador, foi a vanguarda mais expressiva da literatura brasileira. Qual a importância do concretismo para a poesia contemporânea? E, se houver, para o seu ofício de poeta?

Creio que a poesia concreta teve uma importância fundamental para a poesia contemporânea: as polêmicas que ela fomentou ampliaram enormemente o campo de referências da cultura brasileira. Qualquer pessoa da minha geração tem para com ela um débito grande: foram os poetas concretos que colocaram aqui em ampla circulação autores como Pound, Joyce, Mallarmé, cummings, Maiakóvki e outros tantos. Além disso, não fosse a poesia concreta e é provável que por muito mais tempo teríamos permanecido encerrados no estreito nacionalismo que dominou a crítica literária brasileira por décadas. Sem o movimento de ideias gerado por ela é também provável que muito mais gente tivesse continuado marchando em ordem unida na busca do nacional-popular ou no comprazimento demagógico do que se chamou em certo período "literatura engajada". Entretanto, creio que é pouco significativa a presença da poesia concreta - isto é, daquela poesia que se produziu de meados de 1950 a meados de 1960 - na poesia brasileira que se faz hoje. Aqui e ali deparamos com algum poeta marcado pela espacialização combinada com essa praga chamada paronomásia, que é das coisas mais banais de fazer e das menos interessantes de encontrar à superfície de um texto. Mas não creio que a poesia concreta seja uma presença significativa na poesia de hoje. Ao menos, não a que se definiu com esse nome na segunda metade dos anos $50 \mathrm{e}$ começo dos 60. Depois disso, cada um dos poetas concretos tomou um caminho diferente, em que tudo coube, da colagem ao verso mais tradicional, passando pela poesia sem palavras e pela poesia animada em computador. O que até então tinham escrito, mais o que depois escreveram, constitui um dos pólos de força da poesia brasileira do final do século XX. Mas para designar esse conjunto amplo já não faz sentido a expressão poesia concreta.

No que me diz respeito, não penso que haja pontos de contato entre o que escrevo hoje e a poesia concreta ou a poesia produzida posteriormente pelos poetas que ainda temos o costume de denominar concretos. 
8) A pluralidade, a falta de um projeto comum, tornou-se um caracterizador da poesia contemporânea. Mas, para além das diferenças individuais, talvez seja chegada a hora de pensamentear o que une esses poetas, de modo a tentar esboçar uma cartografia da poesia contemporânea brasileira. Você, como leitor crítico da poesia contemporânea, vislumbra alguns denominadores comuns entre os poetas novos?

Em qualquer época é difícil falar em projeto comum. Há sempre projetos de grupos, em conflito uns com os outros e divididos por facções internas. Na verdade, não é o fato de haver um projeto comum, compartilhado pela maioria, que dá o tônus e o desenho aparentemente unificado de um dado momento, quando olhamos para trás. É, sim, a força de algum projeto e a forma como ele conseguiu se impor no seu tempo e depois. É a visada retrospectiva que propõe o cânone, tornando algum projeto a epítome do tempo. Hoje há vários grupos ativos. Então é de supor que deva haver orientações diferentes sobre qual a poesia adequada a este começo de século. Creio, porém, que a novidade deste tempo "pós-utópico" é não só não haver projetos poéticos com implicações culturais amplas, mas não haver tampouco projetos culturais fortes em que a poesia tenha papel de relevo. Há obras individuais de valor, que se destacam no panorama cinzento que lhes serve de fundo e demandam consideração. Talvez por ser esse o meu sentimento sobre o momento, demorar-me sobre os denominadores comuns da poesia contemporânea - o que pressupõe ainda o mapeamento dos grupos - é algo que não anima.

9) Por falar em poesia contemporânea, o desenvolvimento dos meios de comunicação, notadamente a internet, tem interferido substancialmente nas formas de poetar ou trata-se apenas de uma mudança de suporte, de novas formas de difusão da palavra poética?

Os novos meios de comunicação permitiram até agora o desenvolvimento e generalização de um aspecto da literatura: a vida literária. Blogs, revistas eletrônicas, Orkut, Facebook, listas de discussão: temos aí a versão democrática e onipresente da boêmia literária antiga. 
Ao mesmo tempo, os novos meios têm permitido a um número indiscriminado de pessoas a publicação de poemas, bem como o incremento da manifestação pública da opinião, ainda que ligeira, na base do "gostei”, “curti”, com ou sem comentário crítico.

Mas não creio que tenha havido significativa alteração na forma de escrever. No geral, não vejo diferença substancial (não estou pensando em qualidade, mas apenas na forma de escrever) entre o que se publica em portais e revistas na internet e o que depois sai em revistas de papel ou em formato de livro. Pouca coisa é escrita para se esgotar no domínio do virtual, já que a multiplicação caótica dos textos na internet torna relevante a sanção externa da qualidade, que por enquanto parece ser ainda a publicação em papel por uma editora de mercado.

10) Pensando na outra ponta da comunicação poética, o leitor, qual o papel da internet na formação desse leitor? Ou melhor: sem desconsiderar a democratização, a facilidade de acesso aos textos literários por meio da internet, não lhe parece que hoje se forma efetivamente leitores da mesma forma que se formava na Idade Média, com disciplina, rigor, dedicação?

Sou otimista, no que diz respeito à democratização do acesso à literatura propiciada pela internet. Penso que a sua principal novidade esteja no fato de oferecer, a qualquer um que se possa conectar, acesso a um acervo de poesia nunca antes disponível ao indivíduo comum. Entre outras iniciativas, a ampla digitalização de obras literárias para difusão pública e as páginas nas quais se apresentam obras referenciais na forma de hipertexto (como é o caso, para mencionar só duas, de A Divina Comédia e The Waste Land) permitem manter acesa a esperança de que as próximas gerações sejam mais bem informadas, mais lidas, mais capazes de julgamento efetivo sobre a qualidade do presente. A erudição hoje, em suma, parece estar ao alcance dos dedos, reduzida a uma função do Google. É perigoso talvez, pois a informação imediata tende a ocupar o lugar da construção lenta do conhecimento. Mas é estimulante por outro lado, pois o horizonte de referências se alarga desmesuradamente. Não consigo determinar as consequências disso para a leitura e para a escrita, mas não há como não supor que serão de grande relevo. 
11) Ainda considerando o leitor, houve um momento em que os poetas, como é o caso de Mallarmé e dos simbolistas que ele precedeu, deliberadamente optaram pelo afastamento do público mediano e pela preferência por uma recepção mais restrita e seleta. Como você vê a relação entre poesia contemporânea e público mediano, no Brasil?

É difícil dizer qual seja o público de poesia contemporânea no Brasil. Se julgarmos pela tiragem dos livros publicados por editoras, ele parecerá muito restrito. Mas é certo que há muitas formas de difusão da poesia, desde a limitada edição de um livro de autor até a multiplicação infinita das páginas da internet. Mas quando alguém diz "poesia contemporânea" não está pensando nos milhares (ou serão milhões?) de poemas publicados em edições caseiras ou postados em blogues, no Facebook e em sites literários. É uma denominação restritiva (e valorativa) como "MPB”, que recobre apenas uma pequena parcela, que nem é tão popular, da música brasileira. Minha impressão é que quando dizemos "poesia contemporânea" queremos nos referir à poesia que é resenhada em jornais ou revistas culturais, referida por outros poetas e objeto de teses e dissertações acadêmicas. Se esse é o sentido de "poesia contemporânea", seu público é pequeno, em termos numéricos, e muito selecionado, pois parece constituir-se basicamente de acadêmicos e poetas ou aspirantes a poetas. $\mathrm{O}$ que não quer dizer que seja um público homogêneo ou que deixe de ser mediano (a percepção de vários poetas parece aliás ser essa, a julgar pelo número de prefácios ou posfácios acadêmicos nos livros novos e das muitas informações didáticas presentes nos poemas, que em alguns casos mais dramáticos não dispensam sequer a nota de rodapé). Quer dizer apenas que se trata de um público, por assim dizer, especializado ou profissional. Para esse público, a poesia (essa poesia, ao menos) continua sendo objeto de grande interesse. Mas para além desse público, há outro disponível para a poesia contemporânea ou nela interessado? Ou ainda: em que medida essa poesia prevê, na sua fatura, outro público, além do que lhe confere relevância e reconhecimento como objeto cultural significativo? É possível supor que haja um público mais amplo disponível para a poesia, já que as tiragens de livros de prosa ficcional de autores nacionais e estrangeiros são bem mais expressivas; mas minha intuição é que, para esse público, a maior parte da "poesia contemporânea" não tenha o que dizer. Ou não queira dizer. 
12) Qual o papel do crítico e do professor, essas suas outras faces talvez mais conhecidas, no seu exercício de criação?

Creio que essas funções não são antagônicas, pois em medida vária implicam eleição de aspectos do presente, apropriação do passado a partir dessa eleição e aposta em determinados rumos do futuro. Por esse caminho, poderia encontrar alguma forma de ligar as várias formas de escrita e atividade literária. Mas não creio que o crítico e o professor tenham papel preponderante quando estou escrevendo literatura.

13) Está trabalhado em algum projeto criativo novo?

Sim. Estou preparando para publicação, como sempre em ritmo bastante lento, três conjuntos de textos: um livro de contos, um livro de poemas e uma plaquete com os haicais escritos depois de Oeste. E ando trabalhando esporadicamente, nos intervalos, no que talvez se configure como um pequeno romance, de estrutura divertida. 